\title{
ADVOGADAS ROMANAS REPUBLICANAS
}

\author{
REPUBLICAN ROMAN WOMEN LAWYERS
}

Eliane Maria Agati Madeira

\begin{abstract}
Resumo:
O presente artigo examina os textos do historiador romano Valério Máximo (Val. Max. 8.3.1-3) a propósito de mulheres que atuaram como advogadas na Roma Republicana e confronta-os com outras fontes juridicas e literárias que noticiaram a atuação feminina no ambiente forense. Também é objuto de análise a posterior proibição, imposta pelo pretor romano às mulheres, de advogar em favor de terceiros (D.3.1.1.5). A guisa de conclusão, tecem-se algumas considerações sobre a participação da mulher, enquanto advogada, na Roma Republicana.
\end{abstract}

Palavras-chave: Mulher advogada. Proibição de advogar. Valério Máximo.

\begin{abstract}
:
The present article examines the texts of the historian Valerius Maximus (Val. Max.8.3.1-3) concerning women in the roman courts during the Roman Republic period and makes a confrontation between these texts and other juridical and literary sources mencioning women s roles in official court functions. It also examines Ulpian's report of the edict that prohibited women from rupresenting others in court. In conclusion. we made some considerations about women's involvement as a lawyer in the Roman Republic period.
\end{abstract}

Keywords: Women in the courts. Women s prohibition to make applications on behalf of others. Valerius Maximus.

\section{Introdução}

Foi Valério Máximo' quem celebrizou o nome de três mulheres advogadas em Roma, na época da República: Amésia Sência, Afrânia e Hortênsia.

A primeira delas, Amésia Sência, atuou em causa própria na primeira metade do século I a.C. Julgada por uma corte presidida por um pretor, foi absolvida por maioria de votos. Não se sabe ao certo de que era acusada, mas a breve descrição de Valério Máximo nos leva a crer que se tratasse de uma acusação criminal, ${ }^{2}$ seja por ser designada rea, seja pelo relato do procedimento assemelhar-se ao de uma quaestio.

Doutora em Direito Civil pela Faculdade de Direito da Universidade de São Paulo e Especialista $\mathrm{cm}$ Direito Romano pela "Universitá di Roma La Sapienza"

I A obra do historiador romano Valério Máximo. escrita no inicio da época imperial, intitulada Factorum et dictorum memorabilium, é composta por nove livros. No livro VIII, capitulo III. lucaliza-se o tcxto que nos interessa sob a rubrica De mulieribus quae causas apud magistratus egerum.

2 CANTARELlA, Eva. Donne romane da Tacila a Sulpicia. Milano: Feltrinelli, 1996. p. 93. 
Valério Máximo ressalta que Amésia escondia sob o aspecto de mulher o ânimo viril e, por isso, foi chamada de Andrógina.

A segunda mulher descrita por Valério Máximo é Afrânia (ou Carfânia). A mulher do senador Licínio Bucião, que por diversas vezes se dirigiu aos tribunais romanos, é apresentada como arquétipo da intriga feminina, a incomodar o tribunal com seu latratus canino. A confiar na narrativa valeriana, viveu Afrânia até o segundo consulado de Caio César e o primeiro de Públio Servílio, ou seja, até 49 a.C. Da sua atuação nos tribunais se deduziu a proibição romana do exercício da advocacia feminina contida em D.3.1.1.5.

Hortênsia, a terceira consignada, é filha do grande orador Quinto Hortênsio Hortalo. ${ }^{3}$ Sua atuação judiciária associa-se ao ocorrido em 42 a.C, ocasião em que os triúnviros exigiram das mil e quatrocentas mulheres mais ricas de Roma uma contribuição para custear as vultosas despesas militares. Motivada por tal episódio, Hortênsia pronuncia um memorável discurso diante dos triúnviros objetivando dissuadilos de tal posição. O texto de seu discurso nos é relatado por Apiano ${ }^{4}$ e tem por argumento fundamental, para propugnar pelo não pagamento daquele tributo, o fato de as mulheres romanas não terem qualquer atuação política e de serem excluídas da magistratura, dos ofícios públicos e do comando da res publica.

Hortênsia alcança em parte o seu objetivo, pois após sua exposição, os triúnviros refletem e decidem limitar a quatrocentos o número de mulheres obrigadas a pagar o tributo e gravam com novas taxas todos os patrimônios superiores a cem mil denários.

Relaciona-se a este célebre orador (114-50 a.C.) um cpisódio bastante curioso relatado por Plutarco em Vidas Paralelas (Cato Minor, 25-52) e Apiano (Bell. Civ. II, 14, 9). Quinto Hortênsio Hortalo, de aproximadamente sessenta anos, era amigo de Catão Uticense. o qual era casado com Márcia. A filha de Catão, Pórcia, era casada com Bibulo, cônsul em 59 a.C. Desejoso de estabelecer vinculos estreitos com Catão e Bíbulo, Quinto Hortênsio pede ao amigo que the conceda a mão de sua filha Pórcia em casamento. Com ela deseja ter um filho e. em seguida, "restitui-la" ao marido. $\dot{E}$ que. de acordo com a concepção romana, somente a comunhão de filhos e, por conseguinte, de relações familiares. propiciaria estreita relação política e social entre eles. No entanto, ainda que fosse possivel a um pai dissolver o vínculo matrimonial de seus filhos, Catão não acolhe o pedido de Hortênsio. O rétor, então, lhe faz uma derradeira solicitação: que a mulher de Catão, Márcia, case-se com ele. Argumenta que a juventude de Márcia lhe garante ainda uma generosa faculdade de procriação c que não é conveniente que esta venha a pôr em dificuldades o marido dando-lhe mais fithos do que este desejaria. Catão requer um prazo para refletir sobre a súplica do orador e consulta seu sogro. u qual se mostra favorável à idéia. Márcía. entào, que era casada desde aproximadamente 62 a.('. com Catão e que com ele tinha dois filhos, contrai casamento com Hortênsio em 56 a.C., dando-lhe mais dois descendentes. Por ocasião da morte de Hortênsio, em 50 a. $\mathrm{C}$, Márcia, ainda jovem e rica, casa-se novamente com Catão. L'rge notar que o modo pelo qual as fontes referem-se a este acontecimento nos demonstra que tal prática cra socialmente aceitavel. Do ponto de vista juridico, a dissoluçào do primeiro vinculo matrimonial teria sido obtida pelo divórcio.

: APIANO, Bell, Civ., IV. 32-33. 
A advocacia, na Roma Republicana, ainda carente de profissionalismo e permeada pela fides $^{5}$ entre cliente e patrono, não havia sido objeto de intensa regulamentação. Seu exercício, seja por meio de patroni ou oratores ou de iuris periti. pressupunha não-só a aquisição de conhecimentos técnico-jurídicos, como também especialmente retóricos. ${ }^{\circ} \mathrm{A}$ aquisição de tais conhecimentos era normalmente reservada a uma elite que teve oportunidade de se dedicar por longos anos aos estudos. Também algumas mulheres, aquelas bem nascidas, poderiam adquirir o domínio teórico destas ciências.

A sobrevalorização dos elementos retóricus tornou-se patente nos dois últimos séculos da República, época em que, por conta da agitação política do periodo, diversos processos, sobretudo os de natureza penal que se desenvolviam no âmbito das quaestiones, eram acompanhados com interesse pela população e despertavam o interesse pela atuação daqueles que eram seus verdadeiros protagonistas: os advogados. ${ }^{7}$

No que diz respeito às mulheres, não havia qualquer legislação que as impedisse de advogar. Sabe-se que já no período das ações da lei a mulher poderia comparecer em juizo acompanhada de seu tutor ou até mesmo sozinha, como testemunha, como representante de terceiros ou agindo em defesa própria. ${ }^{8}$

No entanto, a presença feminina no ambiente forense não era de todo natural. Apenas a título ilustrativo, constata-se que até mesmo mais adiante, já no denominado período de "emancipação feminina" em época ciceroniana, o simples depoimento de uma mulher em juizo, embora juridicamente possivel, era causa de

5 Para PEREIRA, Maria Helena Rocha. Estudos de História de Cultura Clássica. Lisboa: Calouste Gulbenkian. p. 319 e 323, a fides é uma das "idéias morais e politicas dos romanos" que forma "a parte mais signilicativa do seu legado cultural" Traduz-se especialmente pela "fé nos juramentos, a lealdade. sancionada pelo deus máximo"

- Para se conhecer detalhadamente sobre o exercicio da advocacia em Roma. consulte-se MADEIRA, Hélcio Maciel França. História da Advocacia. origens da profissão de advogado no direito romano. São Paulo: Revista dos Tribunais, 2002, obra na qual há ampla noticia da bibliografia sobre o tema. Ressalte-se que, na República, advocalus é "termo genérico quc compreende tanto os patroni-oratores como os iuris periti ou conselheiros legais", de acordo com MADEIRA, cit., p. 44, n.75.

7 DAVID, Jean Michel. Le patronat judiciaire au dernir siècle de la Republique Romaine. Paris: F́cole Française de Rome, 1992. passim.

8 GIDE, Paul. Énde sur la condition privée de la femme. Paris: Laros et Forcel. 1885. p. 107 e 152.

" A "emancipação". conformi ('ANTAREllA, Eva. Donne romane da Tacira a Sulpicia. Milano: Feltrinelli, 1996. p. $76 \mathrm{e} \mathrm{ss..} \mathrm{iniciou-se} \mathrm{a} \mathrm{partir} \mathrm{do} \mathrm{século} \mathrm{II} \mathrm{a.C.,} \mathrm{culminando,} \mathrm{na} \mathrm{época} \mathrm{de} \mathrm{Augusto,} \mathrm{com} \mathrm{a}$ consagração de uma série de direitos que, gradualmente, a mulher romana adquiriu. Entre os fatores responsáveis por este fenòmeno poderiamos citar: a prevalència do casamento sine mamu, o significado da affectio maritalis. a capacidade sucessória feminina. a transformação da tutela de instituto potestativo a instituso protetivo e. principalmente. as guerras que dizimaram grande parte da população masculina e exigiram das mulheres maior autonomia. 
constrangimento. Cicero. " nas Verrinas. " hipotiza a indignação de Mulleolus ${ }^{12}$ pelo fato de sua esposa, sogra, mãe e avó terem sido constrangidas, contra os costumes, a depor em juizo contra Verres, diante de uma multidão de homens.

$\mathrm{Na}$ órbita específica da advocacia, segundo Gide, ${ }^{17}$ as mulheres teriam abusado tanto deste direito que teriam motivado a proibição de advogarem pro aliis por meio do edito pretoriano comentado por Ulpiano em D.3.1.1.5. Por outro lado, de acordo com Cantarella, a ausência de proibição legal quanto ao exercício da advocacia por mulheres explicava-se pelo fato de ser desnecessária tal medida. Uma exata distribuição de tarefas entre os sexos era a tal ponto interiorizada que sequer se cogitava de uma mulher exercer habitualmente atividades consideradas masculinas. ${ }^{14} \mathrm{~A}$ proibição de advogar teria se dado em decorrência dos perigosos e raros precedentes que Roma vinha experimentando.

Benke também ressalta que antes do edito pretoriano as mulheres romanas teriam gozado das mesmas prerrogativas dos homens no que diz respeito ao exercício da advocacia e considera ser este fato surpreendente numa sociedade fundada no poder patriarcal. ${ }^{15}$

3. A expressa proibição do exercício da advocacia por mulheres em defesa de terceiros

Um edito do pretor, comentado por Ulpiano no título primeiro do livro terceiro do Digesto (de postulando), vetou às mulheres postularem ${ }^{16}$ pro aliis:

\section{D.3.1.1.5 (Ulp. 6 ad ed.)}

Secundo loco edictum proponitur in eos, qui pro aliis ne postulent: in quo edicto excepit praetor sexum et casum. item notavit personas in turpitudine notabiles.

CICFRO, Verr., $11,1,37$ e IV, 45.

1 Verres foi governador na provincia da Sicília por três anos. Exerceu de modo tão cruel e avassalador seu oficio que lngo após ser substituido por $L$. Cecilius Metellus, a maior parte das cidades da Sicilia se reuniu para solicitar que Cícero empreendesse sua coragem e habilidade relórica em uma ação judicial contra o cspoliador.

12 Malleolus, em seu testamento, havia nomeado Verres como tutor de seu filho impúbere. O tutor, entrutanto, cspoliou os bens de seu pupilo. Cicero, em seu discurso, admite hipoteticamente que Malleolus venha repreender seu colega por ter infringido aos deveres de tutor, colega e amigo.

13 GIDE, cit., p. 152.

is Vide CANTARELLA, Eva. Donne romane da Tacira a Sulpicia. Milano: Feltrinelli, 1996. p. 92.

is BENKE, Nikolaus. Women in the courts: an old thom in men's sides. Michigan Journal of Gender and Law, v.3, p. 204, 1995.

16 O conceito de postulare nos é trazido pelo próprio Ulpiano (D.3.1.1.2): Postulare est desiderium suum vil amici sui in iure apud eum, qui iurisdictioni praeest, exponere: vel alterius desiderio contradicere. Mas postular é expor a pretensão própria ou de seu amigo in iure diante daquele que exerce a jurisdição: ou contradizer a pretensão de outro. 
Sexum: dum feminas prohibet pro aliis postulare. Et ratio quidem prohibendi, ne contra pudicitiam sexui congruentem alienis causis se immisceant, ne virilibus officiis fungantur mulieres: origo vero introducta est a Carfania, improbissima femina, quae inverecunde postulans et magistratum inquietans causam dedit edicto Em segundo lugar o edito se dirige contra aqueles que não devem postular no lugar de outros; neste edito excluiu o sexo e os acidentes, bem como designou as pessoas assinaladas com a marca da torpeza.

Quanto ao sexo: enquanto proibe as mulheres de postular em nome de outros. E a razão de proibir é, na verdade, para que as mulheres não se imiscuam em causas alheias, contra a pudicicia correspondente ao seu sexo, nem para que desempenhem oficios masculinos. Sua origem, na verdade, foi introduzida por Carfânia, mulher improbissima, que, postulando de modo vergonhoso $e$ inquietando o magistrado, deu causa ao edito. ${ }^{17}$

É o próprio Ulpiano quem, em fragmentos anteriores, todos constantes do título De postulando, esclarece que "o pretor propôs este título a fím de manter a ordem e de proteger a dignidade e seu decoro, para que não se postule perante ele confusamente, sem distinção" (D.3.1.1 pr) e acrescenta que aqu心le magistrado judiciário estabelecera três tipos de situações em seu edito: a dos que estão proibidos de postular no todo, como os menores de dezessete anos e os surdos; a dos que podem postular apenas em causa própria, como as mulheres, e a dos que podem postular somente por si e por certas pessoas (D.3.1.1).

Curioso, parece-nos, no que diz respeito à proibição de advogar em decorrência do sexo, que um impedimento desta envergadura tenha sido motivado pelo comportamento de uma única mulher. Labruna's entende que se trata de uma acusação infundada atribuir a Carfânia a responsabilidade por esta disposição do edito. Considera possível que esta referência seja decorrente de elucubrações de glosadores eruditos ou de um descuido de Ulpiano ao utilizar-se de precedentes comentários aos editos. Argumenta que o pretor misógino ou sensível, para alcançar a finalidade desejada, teria proibido às mulheres não-somente postular pro aliis, como também as teria tolhido do emprego da palavra em defesa própria nos tribunais. ${ }^{19}$

Sciascia, por sua vez, procura provar a autenticidade da notícia relativa à Carfầnia por meio de referência à obra Iurisperita do poeta latino Títínio que escreveu nos fins do segundo século antes de Cristo. Argumenta o insigne romanista que o

17 Tradução de MADEIRA, cit., p. 95.

is LABRUNA, Luigi. Un editto per Carfania? Synteleia Vincenzo Arangio-Ruiz, 1964.

19 Id. Ibid., p. 420. 
comediógrafo Titinio "provavelmente não teria tratado o assunto da mulher advogada se no seu tempo tivesse havido normas proibindo às mulheres de advogar" ${ }^{20}$ No entanto, a esse propósito Labruna ${ }^{21}$ afirma que Carfânia pode ter sido denominada advogada, mas jamais iurisperita e daí conclui não ser convincente este argumento de Sciascia.

No entender de Benke, ${ }^{22}$ tal referência à Carfânia contribui para atestar o método romano de criação de regras jurídicas a partir de um caso específico exemplar.

Assim como já havia notado Labruna, ${ }^{23}$ também chamou-nos a atenção o fato de a vedação pretoriana não abranger a postulação em causa própria, o que nos permite supor que as diversas atuações judiciais de Carfânia tenham se dado na qualidade de advogada de terceiros. Tal hipótese, no entanto, é aparentemente discrepante com o relato de Valério Máximo, o qual se refure à Carfânia como alguém que pro se semper apud praetorem verba fecit. No que diz respeito a este aspecto, Benke $^{24}$ acredita ser provável que o uso de "pro se" não indique necessariamente a atuação judicial de Carfânia em causa própria, mas enfatize sua atuação diante do pretor diretamente, sem fazer uso de advogados. De qualquer modo, o exercício da advocacia em causa própria, tal qual tolerado, além de ser normalmente excepcional não provoca a indescjada imiscuição feminina em "causas alheias" (D.3.1.1.5).

Conforme assevera Sciascia,, os glosadores defendiam que tal exclusão "não podia valer para as mulheres honestas. Ora, então Carfânia era desonesta? Como nos lembra Rantz, ${ }^{26}$ na tradução do Digesto de Hulot, o termo latino improbissima femina tornou-se "femme très méchante" e Herrmann ${ }^{27}$ insere nossa Carfânia na categoria das mulheres desonestas. Não desejamos correr o risco de conjecturar sobre o que, especificamente, teria provocado tanta ojeriza à figura de Carfânia. Mas as referências de Sciascia a esta "improbissima femina" não só relacionam-se ao seu modo de postular (inverecunde postulans) como também indicam uma velada reprovação, por parte do autor, aos seus comportamentos sexuais.

20 SCIASCIA. Gaetano. Carfănia e as mulheres advogadas. In: VARIETÀ Giuridiche. Scritti Brasiliani di Diritto Romano e Moderno. Milano: Giuffrè, 1956. p. 14-15.

21 Id. Ibid., p.419.

22 BENKE, Nikolaus. Women in the courts: an old thorn in men s sides. Michigan Journal of Gender and Law. v.3. p. 203, 1995.

23 Id. Ibid., p. 420.

${ }^{24}$ Id. Ibid., p. 207.

25 SCLASCIA. Gaetano. Carfània e as mulheres advogadas. In: VARIETÁ Giuridiche. Scrilli Brasiliani di Diritto Romano e Moderno. Milano: Giufliè, 1956. p.16.

26 RANTZ, Berthe. Valère Maxime, VIII, III. Des avocates à Rome? Revue Internationale des Droits de 1 Antiquit: Bruxelles. v. 33, p.186, 1986.

27 HERRMANN, Claudine. Lè role judiciaire et politique des femmes sous la République romaine. Coll. Latomus, 67. p. 122, 1964, apud RAN TZ, cit.. p. 180. 
Valério Máximo, como veremos adiante, acusa-a do delito de maus costumes (mores improbi) e diz que às mulheres acusadas de tais crimes costumou-se denominar Afrânia.

De qualquer modo, as fontes jurídicas expõem co:n clareza as razões pelas quais não se permite às mulheres postular pro aliis: para que nã $\mathrm{s}$ se imiscuam em causas alheias, desempenhando uma atividade em desconformidade com o recato e pudor (pudicitia) considerado inerente ao sexo feminino e por ser esta uma atividade masculina (officium virile).

Retomando o tema relativo à extensão da aplicabilidade do edito pretoriano, consideramos que uma vez inserida a norma naquele documento, assuma esta um caráter de generalidade que é incompativel com a defesa dacjuela tese segundo a qual certas mulheres estariam excluídas da proibição edital. Há que se distinguir a proibição geral de as mulheres advogarem pro aliis. da infeliz catsa do edito pretoriano relacionada ao modo de postular de uma única mulher, trazida à baila para procurar elucidar a origem da norma.

Quanto à eficácia deste edito pretoriano, Sciascia sustenta que nas províncias em que, de acordo com as tradições locais, as mulheres fossem mais independentes, poderiam os magistrados deixar de aplicar tais disposições edilícias. ${ }^{28}$ No entanto, as cláusulas editais não eram, via de regra, decorrentes de elucubrações dos magistrados e sim da influência das práticas ou orientações jurisprudenciais. A esse propósito, nos parece oportuno salientar que o edictum provinciale, emitido pelo governador de província, continha normalmente uma seção em que eram repetidas muitas das cláusulas do edictum praetorium. ${ }^{29}$

É de se notar a seguinte atenuação da incapacidade processual feminina pro aliis reportada pelo jurista Paulo em seus comentários ao ec ito:

D.3.3.41 (Paul. 9 ad ed.)

Feminas pro parentibus agere interdurı permittetur causa cognita, si forte parentes morbus aut aetas impediat, nec quemquam qui agat habeant.

E permitido algumas vezes que as mulheres, causa cognita, dernandem pelos ascendentes, se acaso estiverem doentes os ascendentes ou a idade os impedir, e não tiveram alguém que demande.

\footnotetext{
28 SCIASCIA, Gaetano. Carfânia e as mulheres advogadas. In: VARIFTÁ Giuridiche. Scrilli Brasiliani di Diritto Romano e Moderno. Milano: Giuffrè, 1956. p.17.

29 GUARINO. Antonio. Storia del Dirillo Romano. Napoli: Jovene. 1990. p. 272.
} 
Verifica-se que o magistrado pode excepcionalmente autorizar a atuação judicial feminina na qualidade de advogada de terceiro que seja seu ascendente idoso ou doente. Diante de estranhos permanece a absoluta impossibilidade de postular.

Ora, este fragmento de Paulo reforça a tese de que a verdadeira motivação do edito pretoriano era de excluir as mulheres de uma atividade considerada masculina. na medida em que o exercício da advocacia acarretava o contato com diversos homens estranhos ao círculo familiar e restrito de convivência de uma respeitável mulher romana.

Por fim, através dos comentários de Ulpiano à obra de Massúrio Sabino escrita no I século d.C., verifica-se que não foi apenas no campo da postulatio que as mulheres sofreram restrições ${ }^{30}$ A elas também se proibiu o exercício de qualquer ofício civil ou público, como se verifica a seguir:

D.50.17.2 (Ulp. 1 ad Sab.):

Feminae ab omnibus officiis civilibus vel publicis remotae sunt et ideo nec iudices esse possunt nec magistratum gerere nec postulare nec pro alio intervenire nec procuratores existere.l. Item impubes omnibus officiis civilibus debet abstinere.

As mulheres forum afastadas de todas as funçōes civis $€$ públicas e por isso nem juizas podem ser nem exercer magistraturas, nem postular, nem intervir em favor de outrem nem ser procuradoras. 1. Também o impúbere deve abster-se de todas as funções civis.

Mais uma vez, recorre-se ao aparato jurídico para preencher lacunas da lei que poderiam possibilitar uma variegada atuação feminina na vida pública romana.

4. Breve comentário sobre a Educação feminina em Roma

O exercício da advocacia, ${ }^{31}$ como já tivemos oportunidade de ressaltar, requer capacidade argumentativa e um domínio da linguagem que pressupõe a aquisição de um certo grau de conhecimentos. $O$ aprendizado jurídico normalmente se dava na fase do ensino superior. à qual precedem a escola primária, em que se ingressava por volta dos sete anos para aprender a ler e escrever, e a escola do grammaticus, em cuja sede, a partir dos onze ou doze anos, dedicavam-se alguns jovens ao estudo teórico da boa

30 Também mais tardc esse tipo de proibição se perpetua. Vide ( .2 .12 .21 (315 d.C.), C. Th. 2.12 .5 (393 d.C.) e C.2.12.4, de 204 d.C., que admite que a mulher possa pleitear pessoalmonte, no seu próprio interesse apenas.

3 Diferentemente do advogado, como acentua SCHULZ. Storia della Giurisprudenza Romana. Firenze, 1968, p. 108, o jurista desprezava as palavras e procurava a verdade: res spectatur, non verba penduntur (Cic., Orat., 16.51). 
língua (exercícios de declinação e de conjugação, análise abstrata dos elementos da linguagem etc) e à explicação dos poetas clássicos. ${ }^{32}$

É na escola do rétor (rhetor, orator), na qual os alunos representantes de uma elite estudam até por volta dos vinte anos, que se perfaz o ensino superior. Os alunos são incentivados, após uma série de exercícios preparatórios, a redigir discursos fíctícios e pronunciá-los em público. ${ }^{33}$ Valoriza-se a eloqüência. No entanto, aliado ao propósito de informar sobre a arte oratória, incumbe também ao rhetor (ao menos ao rhetor idealista) fornecer aos alunos elementos que lhes propiciem a aquisição de vasto repertório cultural, como a filosofia, o direito e a história. ${ }^{34} \mathrm{E}$ é também nessa fase, a do ensino superior, que muitas vezes o jovem se inclina ao aprendizado jurídico, o qual pode abrir-lhe as portas de uma promissora carreira.

No que diz respeito especificamente à educação das meninas, parece que muitas destas freqüentavam a escola primária como os meninos. ${ }^{35} \mathrm{O}$ preceptorado privado, no entanto, conforme testemunho de Plínio. o Jovem ${ }^{36}$ (Cartas, V, 16,3), deve ter sido mais utilizado em relação ao sexo feminino, ao menos por aqueles que dispunham de maiores recursos financeiros. ${ }^{37}$

Também no ensino secundário, ainda que reservado a uma elite. participavam lado a lado rapazes e moças, como se depreende de Ovídio. ${ }^{38}$

No entanto, os possíveis conhecimentos adquiridos pelas mulheres romanas tornavam-nas muitas vezes vulneráveis a toda sorte de considerações irônicas. Como acentua Marrou.". "desde as grandes damas da República até as do Baixo Império, a sociedade romana conheceu sempre, pelo menos na aristocracia, um bom numero de mulheres superiormente cultas, e até sábias, sobre as quais os satíricos lançam o ridiculo" 40

32 MARROU. História da Educação na Anliguidade. Tradução Mário Leônidas Casanova. São Paulo: E.P.I!, 1975. p. 412.

33 Id. Ibid., p. 439.

34. Id. Ibid., p. 443-444.

35 F́ o que pode ser concluido a partir dos Epigramas (IX, 68.2) de Marcial, que viveu de 43 a 104 d. C. e cuja obra é importante testemunho da vida c sociedade romanas. Também em Epigramas (VIII,3.16) encontram-sc referèncias ao magister odiado por meninos e meninas bem nascidos.

36 PLÍNIO. Cartas (V, 16,3): Ut notrices et paedagogus, ut praeceptores, pro suo quemque officio diligebat! Quam studiose, quam intelligenter lectitabat!

37 Cf. MARROU. Historia da Educação na Antiguidade. Tradução Mário Leônidas Casanova. São Paulo: E.P.U, 1975. p. 414.

38 OVIDIO. Os Tristes, II, 369-370.

39 Id. Ibid., p. 423.

¿ Vide a propósito MARCIAL, Epigramas, II, 90,9 em que o satírico declara desejar uma mulher que não seja "demasiado sábia" (non doctissima coniunx) e MARCIAL, VII, 69. Vejam-se também CÍCERO, Brutus. 211 que neste caso, de modo elogioso. faz referência às cartas de Comélia, mãe dos Gracos, e à primorosa educação que esta a eles transmitiu e, por fim, SALÚSTIO, Catilina, 25, 2 que assim se refere a uma ex-prostituta, Semprônia, à qual Catilina pretende associar-se: "douta nas letras gregas e latinas, 
Parece-nos certo, porém, que as mulheres, ainda que letradas, não tinham acesso ao tirocinium fori, ou seja, ao ensino prático do direito, em que o aprendiz acompanhava o magister iuris nas suas atividades forenses diárias. As incursões femininas na esfera juridica foram raras e ocasionais, mas suficientes para terem provocado contundentes registros dos juristas romanos a respeito da ignorância feminina em tal área. ${ }^{41}$

\section{Os relatos de Valério Máximo (8.3.1-3) e Apiano}

Valério Máximo, ao tratar "de mulieribus quae causas apud magistratus egerunt" ${ }^{42}$ afirma que não é possível calar-se a respeito daquelas mulheres que nem a modéstia do sexo nem o pudor das vestes femininas ${ }^{43}$ impediram de atuar no foro e nos tribunais:

$\mathrm{Ne}$ de his quidem feminis tacendum est, quas conditio naturae et verecundiae stola ut in foro et iudiciis tacerent cohibere non valuit.

E não podemos deixar de mencionar. [entre os procussos mais insignes]. os daquelas mulheres, cuja elevada condição de natureza ou de reveréncia pela estola não foi razão suficiente para coibi-las de se manifestarem no foro ou nos processos.

Ora, nesta introdução, o historiador manifesta o caráter inusitado da participação feminina no foro e in iudiciiis e ressalta que o impedimento a tal atividade reside na condição natural da mulher (decorrente de seu sexo) e no comedimento e discrição que as vestes femininas tradicionais a ela impõem.

Passa então a expor brevemente a atuação de cada uma dessas mulheres, iniciando por Amaesia Sentia:

Amaesia Sentia rea, causam suam, L. Titio praetore iudicium cogente, maximo populi concursu egit: partesque (ou modosque) omnes ac numeros defensionis non solum diligenter sed etiam fortiter exsequuta et prima actione et

cantava, dançava com mais elegância do que a uma dama honesta convém e possuía todas as mais prendas que são incentivo da luxúria"

$\because \quad$ Ver D.2.8.8.2, D.22.6.8-9 e D.48.5.39.4. $\dot{\mathrm{E}}$ bem verdade que Juvenal 6. 242 acentua que algumas mulheres. em ćpoca imperial. preparavam sozinhas os papéis das causas e eram capacitadas para a defesa verbal, com grande preparo oratório.

42 É importante contextualizar este texto valeriano (8.3.1-3). Com efeito, Valério Máximo, desde o inicio do livro oitavo, dedicou-se a relatar processos de grande e inusitado interesse sob as seguintes rubricas: $d e^{\prime}$ indiciis publicis insignibus, quibus absoluti. indiciis publicis insignibus damnati, iudiciis publicis insignibus ambustae duae, de privatis iudiciis insignibus quibus dammati.

s3 A veste à qual Valério Máximo faz referência é a stola, um vestido próprio das damas romanas de distinção (Conforme, SARAIVA. Novíssimo Dicionário Latino-Porluguês. Rio de Janeiro: Ciamier. 1993). 
paene cunctis sententiis liberata est. Quam, quia sub specie feminae virilem animum gerebat, Androgynem appellabant. Quando Amésia Sência era ré. soh a pretura de Lúcio Tício, defendeu ela a sua causa com enorme afluxo de populares; e cumpriu todas as partes e itens de sua difesa, não somente com diligência, mas também com muita coragem. E já na primeira ação foi liberada e com quase todos os votos. Visto que escondia sob o aspecto de uma mulher um ânimo viril, veio denominada Andrógina.

Alguns aspectos chamam nossa atenção nessa primeira parte do relato valeriano. Trata-se de um processo, esse em que Amésia atuou em causa própria (causam suam), que atraiu grande quantidade de pessoas. Ora, é sabido que processos de natureza criminal (e isso parece estar bem claro pelo emprego dos seguintes vocabulários: rea, prima actio, libertata est e pela referência ao pretor) despertavam a curiosidade do público. O desejo de acompanhar tais processos tornava-se certamente mais intenso quando o acusado fosse uma mulher que tivesse a ousadia (ou simplesmente a necessidade) de defender-se por si só.

A indicação precisa do nome do pretor permite-nos concluir que este fato ocorreu na primeira metade do primeiro século antes de Cristo. ${ }^{44}$ Nessa época. na esfera criminal. já vigorava o sistema das "quaestiones perpetuae" que gradualmente, desde o século II a.C., vinha substituindo a provocatio ad populum e que se generalizou e se consolidou por obra de Sila." As quaestiones, normalmente, eram presididas por um pretor e, na insuficiência de pretores disponiveis, atribuía-se esta função a um iudex quaestionis, uscolhido entre os edis. A menção ao pretor no texto de Valério Máximo reforça a tese segundo a qual, nessa situação especifica, Amésia teria sido submetida a um processo desta natureza. ${ }^{46}$

44 Cf. MARSHAI.L. Roman Ladies on Trial: the case of Macsia of Sentinum. Phocnix. v. XLIV. n. 2, p. 47. 1990 .

15 SANTALUCIA, Bemardo. Le quaestiones perpeluae. In: TALAMANCA. Limeamenti di Storia del Diritro Romano. Milano: Giuffrè. p. 283.

to De acordo com SAVTALUCIA, (op. cil., p. 283-285). o procedimento das quaestiones desenvolvia-se do seguinte modo: um quivis de populo (qualquer cidadão, como representante do interesse público), mediante postulatio, ou seja, mediante prévio reconhecimento por parte do magistrado de que o denunciador tem legitimidade para acusar e, especialmente, honorabilidade, apresenta sua acusação de modo formal (nominis delatio). Aceita pelo magistrado a acusação (nominis receptio). é constituido o colégio de jurados. A composição do consilium foi historicamente bastante alterada e diversas destas modificaçōes indicam a relaçào conflituosa que, nessa época. se travava entre a ordem eqüestre c a oligarquia senatorial. A titulo ilustrativo, verifica-se que em 89 a.C., a lex Plautia ordenou que os jurados fossem escolhidos entre os integrantes das tribos. sem qualquer exigência especifica quanto aos scus estados. Já, uma lex Aurelia iudiciaria, em 70 a.C., determinou que os jurados fossem sortcados a partir de una lista composta. em igualdade numérica, por senadores, cavaleiros e tribuni acrarii. Mais tarde. a lex Iulia de 44 a.C conferiu apenas aos senadores e cavaleiros o mumus indicandi. De qualquer forma. é sabido que o acusado e o acusador poderiam rejeitar os nomes dos sorteados até que ambos concordasscm com a composição dos jurados. Estabelecido o consilium. iniciam-se os debates com as orationes do 
É certo que a habilidade de Amésia, ao discursar, foi certamente dirigida à captação da benevolência dos jurados, os quais não necessariamente dispunham de conhecimentos jurídicos. Sua oratio, portanto, deve ter se pautado pela utilização de recursos que emocionaram o público. Mas não-só isso.

Verifica-se da narração valeriana que já na prima actio foi dado o veredicto. Ou seja, os jurados não titubearam em decidir e não houve necessidade de uma actio secunda ou sucessivas. Sabc-se que. no sistema das quaestiones perpetuac, caso os jurados não chegassem a uma conclusão e fosse por isso elevado o número de abstenções, seria possível o prolongamento dos debates (ampliatio). ${ }^{17}$

A atuação de Amésia foi inicialmente elogiada pelo historiador, pois esta agiu diligenter, fortiter e obteve sua absolvição. No entanto, é manifesta a interpretação de Valério Máximo (e provavelmente de grande parte da sociedade romana da época) do fenômeno: aquelas características de Amésia, responsáveis em grande parte pelo seu sucesso são tipicamente masculinas, próprias do animus virilis; daí ser denominada andrógina. ${ }^{48}$ Sua descrição culmina com uma aparente reprovação.

Há, assim, na visão valeriana, uma verdadeira incompatibilidade entre a feminilidade e o exercício da advocacia (ao menos a advocacia criminal), entre ser advogada e mulher.

No que diz respeito ao coynome Sência, este se refere à cidade umbra de Sentinum, ${ }^{49}$ localizada a aproximadamente cem quilômetros ao nordeste de Roma. Há registros da gens Maesia em Sentinum. No entanto. segundo Rantz, ${ }^{50}$ não devemos empregar, para fazer referência à Amésia, o nome Amésia Sência e sim Amésia de Sentinum. pois a professora de Anvers defende que Amésia não pertenceria à gens Sentia.

As informações contidas no texto valeriano nos indicam que o processo tenha se desenvolvido em Roma. É possível que Amésia tenha se deslocado para Roma ou que já morasse em Roma, embora fosse proveniente de familia de origem diversa. A

acusador e do acusado ou de seu patrono, seguida da oitiva de testemunhas. Encerrados os debates devem os jurados votar pela absolvição ou condenaçâo, inscrindo, a seguir, a tábua de cera (tabella) na qual imprimiam seu voto, na urna. $U$ magistrado, então, recolhe os votos e declara o resultado do escrutinio.

* O próprio Valério Máximo nos relata em 8.1.11 um processo em que apenas no octavo iudicio foi dada a sentença de absolvição. SANTALUCIA. Bernardo. Le quaestiones perpetuae. In: TALAMANCA, Lineamenti di Sturia del Diritlo Romano. Milano: Giuffrè. p. 286, considera que este procedimento pudesse ser adotado apenas para prolongar artificialmente a duração do processo.

18 LiVIO, Tito, 27.11.4 define andrógino como algućm "de sexo incerto, nem menino nem menina"

49 MARSHALL. Roman I adies on Trial: the case of Macsia of Sentinum. Phoenix, v. XLIV, n. 2. p. 46-58. 1990.

so RANTZ, cit. p. 181. 
esse propósito Marshalt ${ }^{-1}$ afirma que nos municípios italianos, depois de 90 a.C., sérios crimes eram transferidos para as cortes romanas, as quais tinham jurisdição criminal sobre os munícipes. ${ }^{52}$ Amésia, de acordo com essa tese, teria sido conduzida à Roma.

Não sabemos se Amésia deliberadamente optou por dispensar a figura de um advogado ou se não pôde dispor de um por razões sociais, políticas ou familiares. De qualquer modo, a habilidade retórica de Amésia e seu nível educacional indicam ser proveniente de classe economicamente abastada, que poderia, em tese, dispor de advogados que a acompanhassem. Talvez sua família a reprovasse e, por isso, não the forneceu qualquer suporte jurídico.

Para refletirmos sobre isso, afigura-se necessário hipotizar de que Amésia era acusada. Não há, na narração de Valério Máximo, qualquer informação que nos permita identificar o crime supostamente praticado por Amésia. No entanto, da análise dos crimes submetidos às quaestiones podemos tecer algumas conseqüentes considerações.

A origem das quaestiones relaciona-se à repressão das repetundae, ou seja. das ilícitas apropriações e extorsões feitas por magistrados romanos em suas províncias, em dano da comunidade ou dos individuos em particular. ${ }^{\varsigma 3}$ Embora sejam escassas as fontes que nos indicam com precisão sobre a época e o modo de inserção das diferentes quaestiones na organização judiciária romana, sabemos que os processos que primeiro foram submetidos a esse tipo de procedimento foram aqueles de natureza política (e.g. crimen maiestatis, peculato, corrupção eleitoral) seguidos, gradualmente, por crimes comuns, como aqueles disciplinados pela lex Cornelia testamentaria nummaria, que sancionou o crime de falso testamento (adulteração de testamento, destruição etc) e a fabricação de moedas falsas, pela lex Cornelia de sicariis et veneficis, que reorganizou a repressão dos homicídios, incêndios dolosos e a da administração ou venda de venenos e pela provável lex (ornelia de adulteriis el de pudicitia. ${ }^{54}$

Tendo em vista a exclusão feminina dos assuntos de natureza pública, resta-nos supor que Amésia tenha sido acusada de um dos seguintes crimes:

si MARSHALI. Roman Ladies on Trial: the case of Maesia of Sentinum. Phoenix. v. XLIV. n. 2. p. 46-58, 1990. Este autor enfatiza ainda que a verdadeira importância deste episódio diz respeito à evidência de que também as mulheres, e năo-somente os homens, podcriam ser submetidas aos tribunais das quaestiones da tarda República.

52 Embora nas provincias fosse formalmente inaplicável o sistema das quaestiones, sabe-se que nos territórios extra-itálicos a persecução criminal era realizada pelos governadores em razão da coercitio com assistincia de um consilium de cidadãos romanos residentes escolhidos livremente pelo governador, o que demonstra que gradualmente no ambiente provincial instalou-se um procedimento análogo ao das quaestiones, conforme atesta SANTALUCIA, Bemardo. Le quaestiones perpetuae. In: TALAMANCA. Lineamenti di Storia del Dirillo Romano. Milano: Giuffri. p. 287-288.

33 Id. Ibid.. p. 280.

is Id. Ibid., p. 280-284. 
envenenamento, homicídio. falso testamento ou, se admitirmos a existência de uma lex de adulteriis et de pudicitia, da prática de adultério.

Ressalte-se que o fato de as fontes literárias serem extremamente escassas quanto a notícias de processos criminais que envolvam mulheres pode ser explicado nãosó pela predominância, no sistema das quaestiones, de processos de natureza políticofinanceira, como também por uma predominância, quanto à mulher, de julgamentos de natureza familiar, desenvolvidos no âmbito doméstico, dada a grande exposição pública ao qual a mulher estaria sujeita quando de sua submissão às quaestiones e, ainda, dado ao provável intimidamento de quivis de populo em denunciá-las. Além disso, no primeiro século antes de Ćristo, a prevalência do casamento sine manu pode ter ensejado a discreta opção de repúdio pelo marido no âmbito de sérias ofensas cometidas na esfera doméstica. ${ }^{\text {ss }}$

É também possivel que Amésia não tenha tido a oportunidade de dispor de figuras do sexo masculino a quem recorrer por desgraças familiares e mortes provocadas pela guerras civis do período. Nesse sentido, ressalta Marshal ${ }^{56}$ que a cidade Sentinum deve ter sofrido as conseqüências danosas das guerras, por ter sido palco da Revolta Umbra de 90 a.C.

Feitas tais observações a respeito de Amésia, vejamos a seguir o que Valério Máximo nos informa a propósito de Afrânia:

C. vero A frania. Licinii Buccionis senatoris uxor, prompta ad lites contrahendas, pro se semper apud praetorem verba fecit: non quod advocatis deficicbatur sed quod impudentia abundabat. Itaque inusitatis foro latratibus assidue tribunalia excrcendo, muliebris calumniae notissimum evasit exemplum; adeo ut pro crimine improbis feminarum moribus C. Afraniae nomen objiciatur. Prorogavit autem spiritum suum ad C. Caesarem iterum, et $P$ Servilium coss. Tale enim monstrum magis, quo tempore exstinctum, quam quo sit ortum. memoriae tradentum est.

C. Afrânia, esposa do senador Licinio Bucião. inclinada a contrair litigios. postulou sempre suas causas diante do pretor, não por falta de advogados. mas porque impudência the abundava. Por consequiência, atormentando os tribunais assiduamente com latidos inusitados pura o fórum, acabou por tornar-se o mais famoso exemplo de calinia feminina. Isto a lal ponto que o nome de $C$. Afrânia é dado ao crime de maus costumes das

MARSHALL, cit., p.54.

ld. Ibid., p. 57-58.

Em apoio a sua original tese, MARSHALL evoca textos de Apiano (1.0.49; 5.30), Dion Cassio 48.13.2-5 e Cicero, Pro Murena 42 que atestam a participação dos umbros nas rebeliōes do periodo e os laços de clientela entre membros da municipalidade umbra e senadores romanos. 
mulheres. Ela prolonga sua existência até o ano ein que Caio César foi pela segunda vez cônsul com Públio Servilio. Pois, em se tratando de tal monstro, a história deve relatar mais a data de seu desaparecimento do que de seu nascimento.

Uma sucessão de elementos trazidos por Valério Máximo em sua descrição de C. Afrânia nos indicam, de modo evidente ou sutil, disparidades entre sua atuação judicial e aquela de Amésia: Afrânia agiu em diversos processos de natureza civil (ad lites contrahendas), Amésia em apenas um de natureza penal; A frânia dispunha de advogados, mas não quis recorrer a eles porque lhe abundava a impudência, o que parece sutilmente indicar que Amésia, diferentemente, não dispunha de advogados e (o que é comprovado pelo relato anterior) não foi socialmente considerada despudorada. Além disso, Afrânia era esposa de senador e, portanto, participava de um círculo seleto de relações. Amésia, diferentemente. apresenta-se como uma desconhecida, identificada apenas por sua cidade natal, competência e bravura. Afrânia invadiu os tribunais e neles fez ecoar sons tão inconvenientes como os latidos dos cães, Amésia, diligenter et fortiter obteve um veredicto quase unânime.

No entanto, em que pesem tais diferenças, o julgamento da sociedade romana da época e do historiador Valério Máximo mostraram-se impiedosos em relação a ambas: Amésia foi designada andrógina e Afrânia, que se tornou exemplo de calúnia feminina, ${ }^{48}$ monstro. Seu nome tornou-se ainda a alcunha das mulheres de maus costumes. A propósito, Benke ${ }^{\vdots 9}$ afirma que provavelmente não empregou o historiador. ao se referir ao comportamento de Afrânia, a palavra crimen em seu sentido técnico.

A Afrânia relatada por Valério Máximo certamente é a Carfânia que deu causa ao edito pretoriano que proibiu às mulheres postularem pro aliis. Os latratus descritos por Valério Máximo coincidem com a postulação de modo vergonhoso (inverecunde postulans) relatada por Ulpiano; a impudentia de Afrânia remete à improbissima femina Carfania; a mulher que deu o maior exemplo de calúnia feminina deve ter sido aquela que nas suas inúmeras aparições deixou o pretor tão constrangido e que deu causa ao edito.

Diante disso, qual seria seu verdadeiro nome? Afrânia ou Carfânia? Sabese que na Litera Florentina, a mulher referida em D.3.1.1.5 é designada ('arfânia. O poeta Juvenal, ${ }^{, 0}$ entretanto, refere-se a ela como Carfinia. Nos manuscritos da Glosa

58 O crimen calumniae é um delito quc consiste em emitir acusações falsas e infundadas em relação a sujeitos inocentes. Conforme o jurista Marciano (D.48.16.1.1): calumniare est falsa crimina intendere.

59 BENKE. Nikolaus. Women in the courts: an old thom in men's sides. Michigan Journal of Gender and Law, v.3. p. 211,1995 . n. 68.

60 JUVENAL. Sat. 2.69: ".... Damnetur si vis, etiam Carlinia: talem non sumet damnata togam" 
(Vulgata) seu nome é Calphurnia. ${ }^{\text {il }}$ Sustenta Sciascia ${ }^{62}$ que o verdadeiro nome dessa mulher seja Caia Afrânia por ser este um nome romano. Assim. a variação da grafia se explicaria por um provável erro de cópia pelo cual a abreviatura do prenome teria se unido ao sobrenome (nome gentilício), conforme já consignado por Andrea Alciato no século XVI. Fm seguida, teria havido a transposição da letra r. O romanista napolitano Labruna ${ }^{\prime \prime}$ atribui tais diferenças às "trivializações" dos glosadores ou dos escribas de origem grega.

Sobre o específico comportamento de Carfânia (além de sua exagerada inclinação por demandar. sua voz irritante e sua impertinência), que teria deixado o magistrado tão irado a ponto de publicar o referido edito, nada se sabe. Seja como for, o espirito de chicana que motivava Afrânia a intentar tantos processos, por si só, certamente, seria suficiente para irritar o pretor que atuava na fase in iure do procedimento formulário.

Finalmente, passemos à análise da última parte do capítulo terceiro do livro oitavo de Valério Máximo.

Hortensia vero, Q. Hortensii filia, quum ordo matronarum gravi tributo a triumviris esset oneratus, nec quisquam virorum patrocinium eis acconmodare auderet, causam feminarum apud triumviros et constanter et feliciter egit: repraesentata enim patris facundia, impetravit, ut major pars imperatae pecuniae his remitteretur. Revixit tum muliebri stirpe Q. Hortensius, verbisque filiae adspiravit. Cujus si virilis sexus posteri vim sequi voluissent, Hortensianae eloquentiae tanta hereditas una feminae actionc abscissa non esset.

Hortênsia, filha de Q. Hortênsio, vendo as mulheres de Roma oneradas pelos triúnviros por um pesado imposto. sem que nenhum homem ousasse lhes apoiar, postula sua causa diante do tribunal dos triunviros, com firmeza e sucesso. Fiel imagem da eloquiência de seu pai, ela oblém a diminuição de grande parte da taxa imposta a seu sexo. $Q$ Hortênsio parecen reviver naquela mulher e respirar no discurso de sua filha. Se seus descendentes masculinos tivessem desejado seguir esta vigorosa força, não haveria una tão grande herança da eloqüência de Hortènsio reservada para uma inica obra de uma mulher.

A habilidade de Hortênsia em seu discurso (constanter et feliciter egit) e seu excepcional emprego da oratória fizeram que Valério Máximo não pudesse deixar de

6) Como atesta SCIASCIA. Gaetano. Carfannia e as mulheres advogadas. In: VARIETÀ Giuridiche. Scritti Brasiliani di Diritto Romano ' Moderno. Milano: Giuftri, 1956. p.13.

62 Id. Ibid., p. 13-14.

${ }^{63}$ LABRUNA, Luigi. Un cditto per Carfania? Symeleia Vincenzo Arangio-Ruiz, 1964, p. 420 
elogiá-la. No entanto, relaciona sua capacidade de comunicação e persuasão à herança paterna, minimizando o valor e a originalidade da atuação de Hortênsia, um claro sinal de que, de acordo com certas concepções masculinas da época, os dotes intelectuais femininos justificar-se-iam apenas geneticamente. O sucesso e a segurança demonstrados por Hortênsia são, assim, apenas reflexos da grandeza da eloqüência paterna.

A participação de Hortênsia neste episódio é inicialmente justificada pela recusa ou ausência de homem que se dispusesse a aceitar o encargo (nec quisquain virorum patrocinium eis accommodare auderet), provavelmente o mesmo que ocorreu com Amésia.

Atuou Hortênsia como porta-voz de diversas mulheres, as mil e quatrocentas mais ricas de Roma, dentre as quais ela se incluía. A filha do célebre orador romano que foi cônsul em 69 a.C. era também mãe adotiva de Brutus, o que lhe dava ampla projeção social. Embora sua postura e atuação em nada lembrem aquela de Afrânia, nota-se um ponto de contato entre tão díspares mulheres: a proximidade do poder e de semelhantes círculos político-sociais.

Mas enquanto Amésia e Afrânia atuaram na órbita judicial propriamente dita, seja no âmbito penal ou civil, na qualidade de advogadas em causa própria, a atuação de Hortênsia diante de Otaviano, António e Lépido foi uma representação popular, fora do tribunal, na qualidade de lider de uma manifestação de caráter político. ${ }^{6:}$ De qualquer modo, Hortênsia exerceu a advocatio, pois postulou perante autoridade jurisdicional. ${ }^{6.6}$

Não é só através de Valério Máximo que podemos țr noticias de Hortênsia. Também Quintiliano, ${ }^{66}$ nas Instituições Oratórias, ao tratar da importância dos pais, avós e criados na educação infantil, refere-se brevemente à Hortênsia, demonstrando o quanto os exemplos e valores transmitidos pelos pais podem ser essenciais para o futuro de um cidadão.

Mas é em $\mathrm{Apiano}^{67}$ que encontramos a reprodução daquele que teria sido o próprio discurso de Hortênsia. Naquele momento. em 43 a.C., os triúnviros tinham

6. Nesse sentido SCIASCIA, Gaetano. Carfânia e as mulheres advogadas. In: VARIETÁ Giuridiche. Scritri Brasiliani di Diritto Romano e Moderno. Milano: Giuffrè, 1956. p. 17 e LABRUNA, Luigi. Un editto per Carfania?. Synteleia Vincenzo Arangio-Ruiz, 1464. p. 418, n. 20

65 Remetemus u leitor novamente ao conceito de postular exposto por Ulpiano em D.3.I.I.2.

${ }_{66}$ QUINTILIANO. Instimiçōes Oratorias, I, I.VI: In parentibus uero quam plurimum esse eruditionis optanerim.

Nec de patribus tantum loquor. nam Gracchorum eloquentiae multum contulisse accepimus Corneliam matrem, cuius doctissimus sermo in posteros quoque est epistulis traditus. el Laelia C. filia reddidisse in loquendo paternam elegantiam dicitur; et Hurtensiae Q. filiae orutio apud triumuiros habita legitur non tantum in.

sexus honorem.

6. APIANO. B.C., IV, 32-34. 
necessidade de vinte milhões de denários aproximadamente. Rcuniram então uma assembléia popular e propuseram um edito que obrigava as mil e quatrocentas mulheres mais ricas e mais nobres de Roma a fornecer uma declaração de suas fortunas e a contribuir em uma taxa que seria fixada pelos triúnviros. Provavelmente, como acentua Nicolet. ${ }^{68}$ a razão desta medida residia no fato de o grande número de patrimônios terem sido transferidos, por conta das guerras civis, às herdeiras, as quais não estavam sujeitas às medidas fiscais relacionadas à pessoa do contribuinte. Inicialmente as mulheres procuraram a intervenção da irmã de Otaviano e da mãe de Antônio, que eram simpáticas à causa, mas Fúlvia, mulher de António, as expulsa e recusa-se a interferir em favor delas. As mulheres, então, caminham em direção ao Fórum e atribuem a uma dentre elas, Hortênsia, a função de representá-las. A atuação de Hortênsia é, assim, decorrente de uma tentativa frustrada de "mediação familiar" ${ }^{6 "}$

A célebre oratio de Hortênsia. tal qual relatada por Apiano, inicia-se com a lembrança dos pais, filhos, esposos e irmãos que lhes foram subtraídos, sob o pretexto de serem inimigos. E então, Hortênsia sugere-lhes: "Sc vós nos considerais inimigas, inscrevei-nos nas tábuas de proscrição" ${ }^{70}$ A seguir, no ponto culminante de seu discurso, questiona: "Por que vós desejais a nossa contribuição, se não participamos das magistraturus, nem das funções de comando e de governo pelas quais vós disputais?"

Hortênsia recorda, por fim, a oportunidade em que as matronas, por ocasião das Guerras Púnicas, voluntariamente contribuíram com as despesas de guerra doando ao erário suas jóias, e não suas terras ou dotes, sım qualquer receio de delatores 1 como na atual situação.

Da análise do discurso de Hortênsia, verificam-se dois argumentos substanciais para propugnar pelo não-pagamento dos tributos que são impostos àquelas mulheres. Um deles, de caráter social, é o de que tais tributos trariam danos consideráveis às matronas, a quem o patrimônio imobiliário e os bens dotais ${ }^{72}$ asseguravam a subsistência. Não se tratam apenas de prejuízos de ordem econômica, mas de assegurar às mulheres livres a liberdade necessária, para a qual os recursos

68 NICOLET, Claude. Le métier de ciroyen dans la Rome républicaine. Paris: Gallimard, seconde cdition. p. 245.

69 Cf. PEPPE, cit., p. 26.

70 DE MARTINO. Storia della costituzione romana. Napoli: Jovene, 1974. v. 4. p. 78 nos esclarece a respeito da Lex Titia que regulamentou os poderes extraordinários dos triúnviros. O edito com a lista das proscrições foi publicado imediatamente em segusida a esta lii.

7 Os delatores seriam recompensados caso indicassem fraudes nas declaraçües de bens das matronas.

72 A inclusão dos bens dotais em tal categoria pode, a principio, nos causar certa estranheza pelo fato destes bens não pertencerem juridicamente à mulher. PEPPE, cil.. p. 30, nota que tal menção poderia significar a restituição, para as mulheres. dos bens dotais por ocasião da proscrição de seus maridos. 
financeiros contribuem de modo fundamental. Nesse sentido, Peppe ${ }^{73}$ evidencia na alegação de Hortênsia aqui referida, três diversos momentos de consciência social: um, relacionado ao grupo de origem dessas mulheres, com conotação de tom nitidamente aristocrático; outro, que diz respeito aos seus próprios costumes e modo de viver e, por fim, o que se refere à própria natureza feminina, apresentada pela oradora como diversa da masculina.

O outro argumento trazido pela arguta oradora, de caráter político (ou melhor, apolitico) é o de que não há necessidade de contribuição financeira por parte de quem não participa das decisões relativas à res publica. Cantarella, a esse propósito, ressalta que nas colônias inglesas da América do Norte, o princípio "No taxation without representation" será, muitos séculos mais tarde, utilizado para reivindicar direitos políticos a quem fosse gravemente onerado com o pagamento de taxas. Justamente o inverso de nossas matronas romanas que se valeram da exclusão feminina da órbita politica para justificar a inoponibilidade de seus patrimônios. ${ }^{74}$

Terminado o discurso de Hortênsia. os triúnviros, bastante irritados com tal ousadia, ordenam a seus lictores que dispersem as mulheres do foro, no que não foram bem-sucedidos. Os triúnviros, então, remetem ao dia seguinte o exame da questão. $^{\text {"5 }}$

Como conseqüência do pronunciamento de Hortênsia, no dia seguinte, o número de mulheres sujeitas àquela contribuição foi reduzido de mil e quatrocentos para quatrocentos, mas foi decidido que qualquer pessoa que tivesse patrimônio de ao menos cem mil denários também contribuiria.

\section{Conclusão}

Após termos analisado estes textos, afigura-se nítida a excepcionalidade da atuação feminina na qualidade de advogada, em época Republicana.

Ainda assim. entenderam os romanos ser essencial, para evitar a disseminação de um padrão de comportamento contrário à tão desejada pudicitia feminina, coibi-las de postular pro aliis.

73 PEPPE. cit., p.31.

74 PEPPE, cil., p. 43 considera que este argumento reproduza uma correntc de pensamento relativamente difusa em Roma e encontra familiaridades entre tais elementos e o conteúdo do discurso do tribuno Lúcio Valério a favor da ab-rogação da Lex Oppia (Tito Livio, 34,7,8-9). Sobre a Lex Oppia, vide artigo de nossa lavra: La Lex Oppia el la condition juridique de la femme dans la Rome républicaine in Revuc Internationale des Droits de l'Antiquité. LI. 2004, pp.87-100.

7s APIANO. B.C., IV, 33-34. 
Resta-nos associar à trajetória destas e de outras mulheres anônimas que ousaram dedicar-se ao direito em Roma o mito da célebre Tácita Muta, outrora ninfa Lara, expansiva e falante, que pelo uso desmedido de suas palavras foi penalizada por Júpiter com a perda de sua habilidade comunicativa e reduzida, assim. à qualidade de deusa do silêncio.

São Paulo, dezembro de 2006.

\section{Referências}

BENKE, Nikolaus. Women in the courts: an old thorn in men's sides. Michigan Journal of Gender an Law, Michigan, 1995.

CANTARELlO, Eva. Donne romanae da Tacita a Sulpicia. Milano: Feltrinelli. 1996.

DAVID, Jean Michel. Le patronat judiciaire au dernir siècle de la Republique Romainc. École Française de Rome, Paris, 1992.

DE MARTINU. Storia della costituzione romana. Nápoles: Edittore Jovene, 1990.

GIDE, Paul. Étude sur la condition privée de la femme. Paris: Larus et Forcel, 1885.

GUARINO, Antonio. Storia del Diritto Romano. Nápoles: Edittore Jovene, 1990.

HFRRMANN. Claudine. Lê role judiciaire et politique des fermmes sous la République romaine. Coll. Latomus, 1964.

LABRUNA, Luigi. Un editto per Carfania? Synteleia Vicenzo. Arangio-Ruiz, Milano, 1964.

MARROU. História da Educação na Antiguidade. Tradução de Mário Leônidas ('asanova. São Paulo, E.P.U., 1975.

MARSHALL. Roman Ladies on Trial: the case of Maesia of Sentinum. Phoenix. v. XLIV. 1990.

MÁXIMO, Valério. l'actorum et dictorum memorabilius, Livro VIII: Capítulo III: "De mulieribus quae causas apud magistratus egerunt"

NICOLET, Claude. Le métier dé citoyen dans la Rome Républicaine, Gallimard, seconde edition. Paris, 1990 .

PEREIRA, Maria Helena Rocha. Estudos de História de Cultura Clássica. Lisboa: Calouste Gulbenkian, 1996. 
RANTZ, Berthe. Valère Maxime, VIII, III. Des avocates à Rome? Revuc Internationale des Droits del'Antiquité. Bruxelles, 1986.

SANTALUCIA, Bernardo. Le quaestiones perpetuae. Talamanca. Lineamentos di Storia del Diritto Romano. Milano: Edittore Giuffrè. 1990.

SCIASCIA, Gaetano. Carfânia e as mulheres advogadas. Varietà Giuridiche. Scritti Brasiliani di Diritto Romano e Moderno. Milano: Edittore Giuffrè, 1956. 